\section{New Attachment After Treatment of Intrabony \\ Defects in Monkeys}

by

\section{Birgit EllegaARD*}

THORKILD KARRING*

RoBin Davies**

HARALD LÖ $\ddot{O E}^{* * *}$

New ATTACHMENT PROCEDURES in intrabony defects involve removal of the pocket epithelium and establishment of a blood clot. Subsequently fibrogenesis, cementogenesis and the formation of new bone take place. To this end a multitude of clinical methods have been advocated: (1) "blind" curettage, (2) various surgical techniques combined with curettage, and (3) grafting of various materials intended to promote osteogenesis.

During the last 15 years free autografts of cancellous or compact bone have been used in the treatment of intrabony defects by several investigators. ${ }^{1-12}$ There is also evidence that chips of cementum and dentin may stimulate bone tissue formation. ${ }^{13,14}$ Furthermore, autogenous fresh and frozen hip bone marrow has been introduced recently to obtain new attachment. ${ }^{15-21}$

Although clinically successful results have been reported, opinions differ regarding the effectiveness of heterogenous bone grafts. ${ }^{22,} 23$

Very few studies have been designed to evaluate the effectiveness of the various procedures in establishing new attachment. The purpose of this investigation was therefore:

1. To develop an animal model for clinical and microscopic study of the treatment of three-wall intrabony defects.

2. To compare the effect of new attachment procedures including the grafting of autogenous cancellous bone, fresh and frozen hip bone marrow.

3. To study microscopically the healing pattern and

\footnotetext{
*Department of Periodontology, Royal Dental College, Aarhus, Denmark.

**Turner Dental School, Manchester, England.

***Dental Research Institute, University of Michigan, Ann Arbor, Michigan.
}

mode of regeneration with and without the various graft materials.

\section{PART I-ESTABLISHMENT OF THE MODEL}

\section{Materials AND Methods}

A total of 93 three-wall intrabony defects were produced adjacent to the permanent incisors, canines and molars of 8 Rhesus monkeys.

After general anaesthesia had been induced by intramuscular injections of $0.5 \mathrm{mg} / \mathrm{kg}$ Sernylan (Pencyclidine hydrochloride) and by intravenous injections of Nembutal, the lateral incisor and a premolar in each side of the upper and lower jaw were extracted. In the crowns of the teeth, small amalgam fillings were placed as reference points.

After reflection of mucoperiosteal flaps, three-wall intrabony defects were produced by removing the bone with a No. 1 fissure bur and chisel. The defects were created on the distal surface of the central incisors and canines, and on the palatal aspect of some maxillary molars. The mesiodistal width of the defects was approximately $3 \mathrm{~mm}$. A notch was made in the root surface at the bottom of each defect and the depth of the intrabony lesion was determined by measuring the distance from the notch to the margin of the bone with a graduated probe. The distance from the amalgam reference point to the bottom of the defect was also measured.

To prevent spontaneous healing, 40 intrabony defects were filled with periodontal dressing. In 31 a steel band trimmed to conform to the shape and size of the defect was fixed to the tooth with a wire (Figure 1). In 15 defects a steel band as well as a small amount of dressing were placed against the root surface. The flaps were replaced and sutured. The dressing and/or the bands were left in place for four weeks, during which period the monkeys were fed a soft diet.

After observation periods of 1 to 24 weeks the animals were sacrificed by an overdose of Nembutal. Before sacrifice, the distance from the amalgam reference point to the gingival margin and to the bottom of the defect was measured. The jaws were dissected and immediately placed in 10 per cent buffered formalin. Decalcification took place in EDTA, and after embedding in paraffin, 6 micron serial sections were cut and stained with hematoxylin and eosin and with Mallory's connective tissue stain. Eighteen specimens were macerated for macroscopic analysis of the bony defects.

\section{Observations}

Clinically, plaque deposits, chronically inflamed gin- 


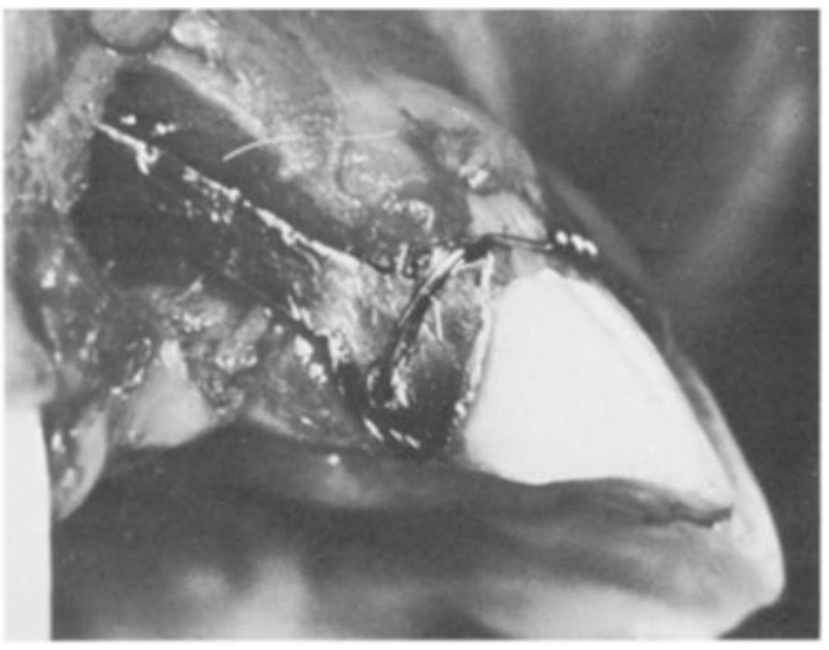

FIGURE 1. A three-wall intrabony defect produced adjacent to the central incisor of a rhesus monkey. A steel band is wired to the tooth to prevent spontaneous healing.

giva and pocket formation were evident in the areas subjected to surgery. In the majority of the defects, the distance from the reference point to the bottom of the pocket had not changed during the experimental period. In a few cases the depth of the lesion had increased and spontaneous healing was observed in some defects from which the pack had been lost prematurely.

In most cases the gingival margin had retracted 1-2 $\mathrm{mm}$ during the postsurgical period.

\section{Microscopy}

Of the 75 intrabony defects processed for microscopy, 49 displayed signs characteristic of a chronic periodontal lesion. In 15 cases spontaneous healing had occurred, probably as a consequence of early loss of the periodontal dressing. Eleven lesions developed horizontal bone loss to the level of the notch in the root surface. The latter tended to occur when two adjacent defects were originally separated by a thin bony septum.

The remaining 49 intrabony lesions exhibited varying degrees of chronic inflammation in the connective tissue and apical migration of the pocket epithelium. In some 2 and 3 week specimens, the epithelium extended approximately to the bottom of the defects, whereas in others the pockets were only partly epithelialized. After 4 weeks all intrabony lesions were entirely epithelialized. The thickness of the epithelium in most instances measured 8-10 cell layers in the middle portion, tapering off to a single layer at the bottom of the pocket. Generally, the base of the pocket epithelium coincided with the notch in the root surface. However, in a few specimens new attachment had occurred in a small area adjacent to the notch. Below the notch the attached fibers extended from the cementum in a coronal direction towards the crestal portion of the alveolar bone. Some fibers were attached to the bone; others fanned out into the gingiva or reached across to the adjacent tooth. The connective tissue showed slight to moderate infiltration of inflammatory cells throughout the experimental period. In most long-term specimens the width of the defects had decreased. It appeared that the root surfaces had often been damaged during production of the bony defects (Figures 2, 3).

\section{PART II-NEW ATTACHMENT STUDIES IN THE THREE-WALL INTRABONY DEFECT}

\section{MATERIALS AND MethodS}

In this part of the study 12 adult Rhesus monkeys were used. Under general anaesthesia 94 intrabony defects were produced, as described in Part I. Reference points were made by placing small amalgam fillings in the teeth adjacent to the intrabony defects. After periods of 8-10 weeks the monkeys were again anesthetized. The depth of the periodontal pocket was determined by measuring the distance from the reference point to the
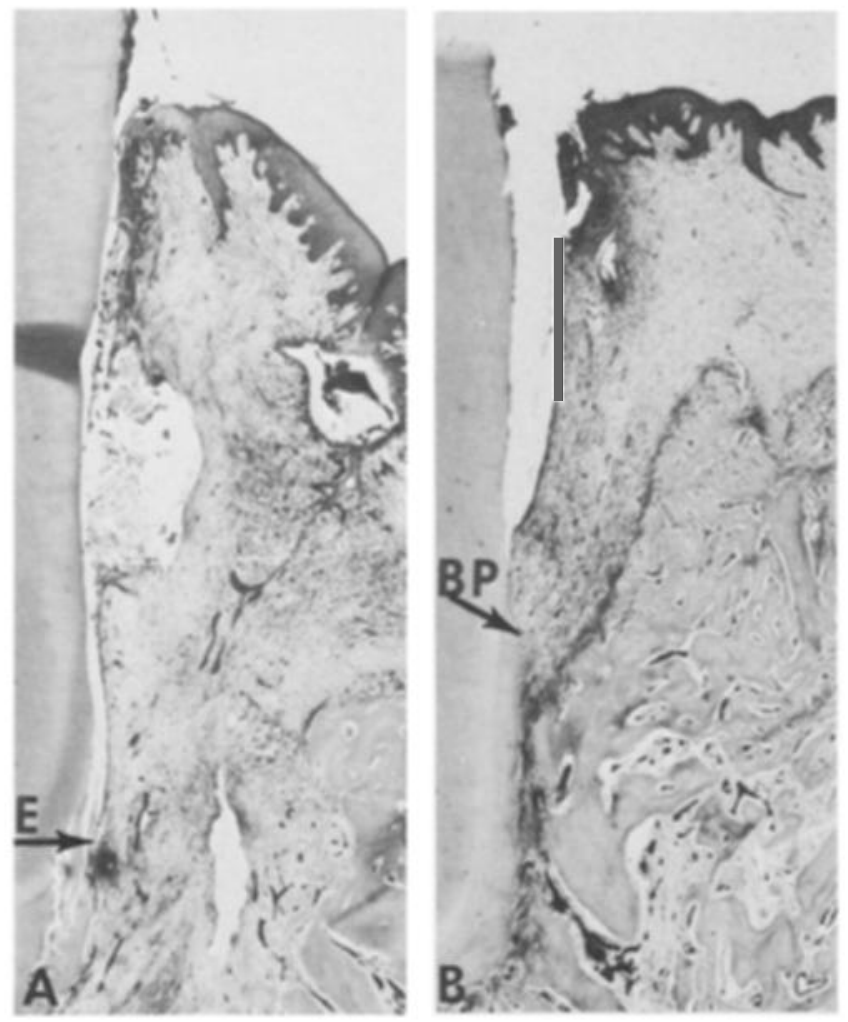

FIGURE 2. A: Photomicrograph showing a section from a 4-week-old three-wall intrabony defect with heavy infiltration of inflammatory cells and a thin epithelial lining $(E)$. B: Eight-week-old three-wall defect with epithelial lining extending into the intrabony area. New attachment in the apical portion of the defect $(\mathrm{BP})$. 


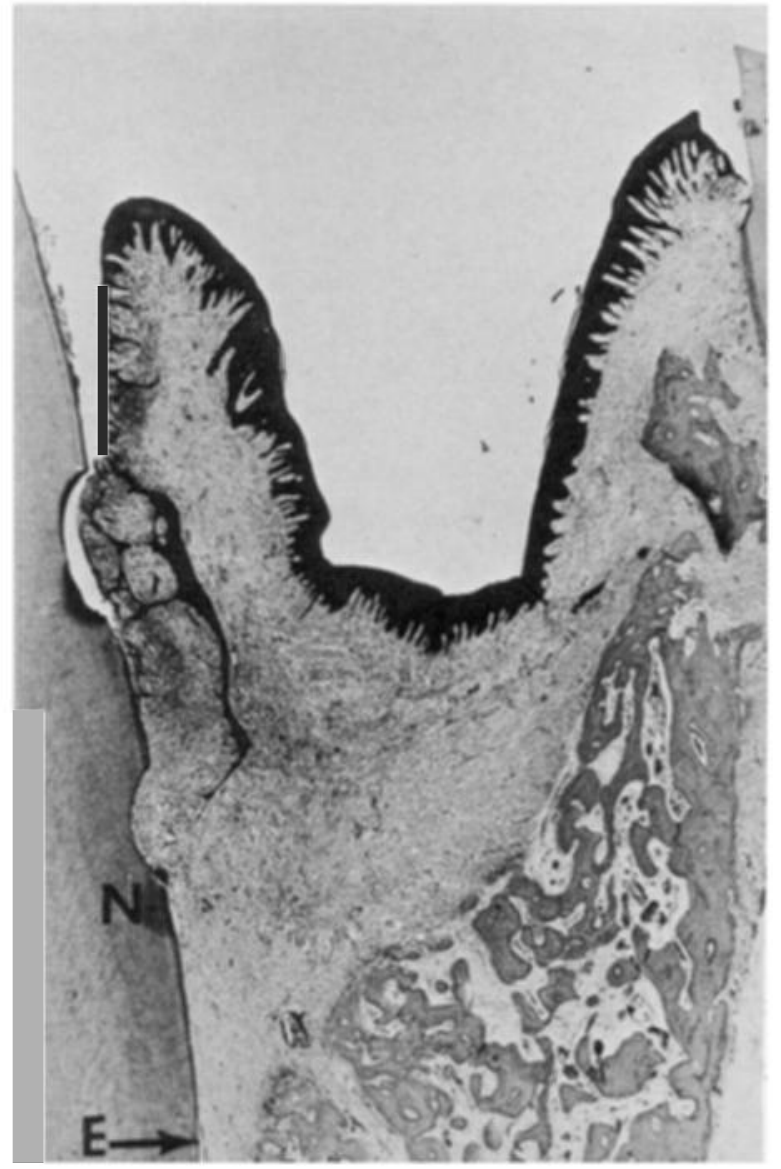

FIGURE 3. Photomicrograph showing a 24-week-old three-wall intrabony defect. The epithelium $(E)$ has migrated beyond the notch $(N)$ at the bottom of the defect.

gingival margin and from the reference point to the base of the lesion. A reverse bevel incision was made and mucoperiosteal flaps were reflected on the buccal and lingual aspects of the jaw. All soft tissue was removed from the intrabony defects by means of curettes and the root surfaces were planed to a smooth hard finish. With a small bur notches were produced in the root surface at the bottom of the defect and at the level of the alveolar crest. At this point the following measurements were made using a graduated probe:

The greatest distance from the crest of the alveolar bone to the bottom of the bony defect.

The distance from the amalgam reference point to the bottom of the defect.

The area was irrigated with sterile isotonic saline and where the bony walls of the crater were dense and sclerotic, multiple openings were made with a small bur.

Young autogenous cancellous bone was transplanted to 27 defects. This graft material was obtained from an area of the upper jaw, where two premolars had been extracted 12-16 weeks previously.

Fresh autogenous hip bone marrow was transplanted to 24 defects and frozen autogenous hip bone marrow to 23 defects. The bone marrow was removed from the hip using a Westerman-Jensen bone marrow biopsy needle. The fresh marrow cores were transferred directly to the defect or placed for a short time on a gauze pad moistened with a $0.9 \%$ saline solution. Other specimens were placed in 50\% glycerol in Minimum Essential Media, frozen to $-79^{\circ}$ with a cooling rate of $1-2^{\circ}$ $\mathrm{C} / \mathrm{min}$. and stored at $-79^{\circ}$ until use. Prior to insertion the core was rapidly thawed to $37^{\circ}$ and sectioned on a moistened gauze pad.

No transplant was used in 20 defects.

The flaps were carefully replaced and sutured to ensure that the lesions were adequately covered. Periodontal dressing was not used. The monkeys received 600,000 I.U. Bicillin intramuscularly immediately prior to surgery. The sutures were removed after one week.

The experimental procedures were scheduled to allow observation periods of $1,2,3,6,12$, and 24 weeks. All four types of treatment were represented in each monkey. The monkeys were sacrificed with an overdose of Nembutal. Clinical measurements of the pocket depth were made one week before sacrifice in the 12 and 24 week specimens.

Histologic processing was as previously described.

\section{Criteria for Evaluating the Results}

Clinically the amount of new attachment was assessed in 12 and 24 week specimens on the basis of pre- and postoperative measurements of the distance from the amalgam reference point to the bottom of the pocket. Postoperative depth of the periodontal pocket was also recorded.

The length of the connective tissue attachment and/ or ankylosis was measured in $\mathrm{mm}$ from photomicrographs in a section from the middle portion of each specimen. Regeneration constituting between 75 and $100 \%$ of the original depth of the defect (the distance between the notches) was considered as complete regeneration, between 50 and $75 \%$ as partial regeneration, and less than $50 \%$ as a failure.

In the same sections the depth of the periodontal pocket was measured from the gingival margin to the apical location of the epithelium (Table I).

\section{RESULTS}

When the 26 clinical measurements were compared with those obtained from the histologic sections, 7 were 
identical, 4 showed less and 15 showed more new attachment than the microscopic measurements. Postsurgical shrinkage of the gingival margin ranged from 0 to $3 \mathrm{~mm}$. The clinical pocket depth varied between 1 and $6 \mathrm{~mm}, 13$ showed pockets of 1 to $2.5 \mathrm{~mm}$. and 13 showed pockets of 3 to $6 \mathrm{~mm}$.

\section{Histological Findings}

Although regeneration occurred after all procedures, the frequency and extent of new attachment varied. Seventy-three of the 94 treated intrabony defects were evaluated. One and two week old specimens and incorrectly embedded preparations were not used for quantitation. Complete regeneration as evidenced by formation of cementum, connective tissue and bone, including those specimens with ankylosis, occurred in 66.7 per cent of the teeth grafted with cancellous bone, in 88.2 per cent of those treated with fresh bone marrow, in 84.2 per cent of those with frozen marrow, and in 56.3 per cent of the defects without grafts. Partial regeneration took place in 23.8 per cent of those treated with cancellous bone and in 25 per cent without grafts. Failure was recorded in 9.5 per cent of the teeth treated with cancellous bone, in 11.8 per cent with fresh marrow, in 15.8 per cent with frozen marrow, and in 18.7 per cent without grafts (Figure 4).
Since cases with ankylosis were recorded as regeneration, the percentage of specimens showing complete regeneration does not express the amount of new attachment obtained. Using new cementum formation and development of a periodontal ligament as the criteria for new attachment, only 48.5 per cent of the teeth treated with cancellous bone, 6.5 per cent of those with fresh marrow, 68 per cent with frozen marrow, and 56.3 per cent without transplants showed complete new attachment (Figure 5).

Connective tissue attachment to the cemento-enamel junction was never observed. Evidence of epithelial downgrowth along the root surface was seen in all specimens. Depth of the pockets varied between 1 and 7 mm. (Figure 6).

\section{Healing Pattern}

After one week the blood clot was partly organized. A fibrin network was seen in some portions, but remnants of the clot were present in all specimens. Osteogenic activity was seen on the bony walls of the defects, whereas a marked resorption occurred at the alveolar crest. Bone formation was observed in localized areas adjacent to the grafts. At this stage there was no sign of cementum formation. The epithelium extended approximately to the notch which designated the level of

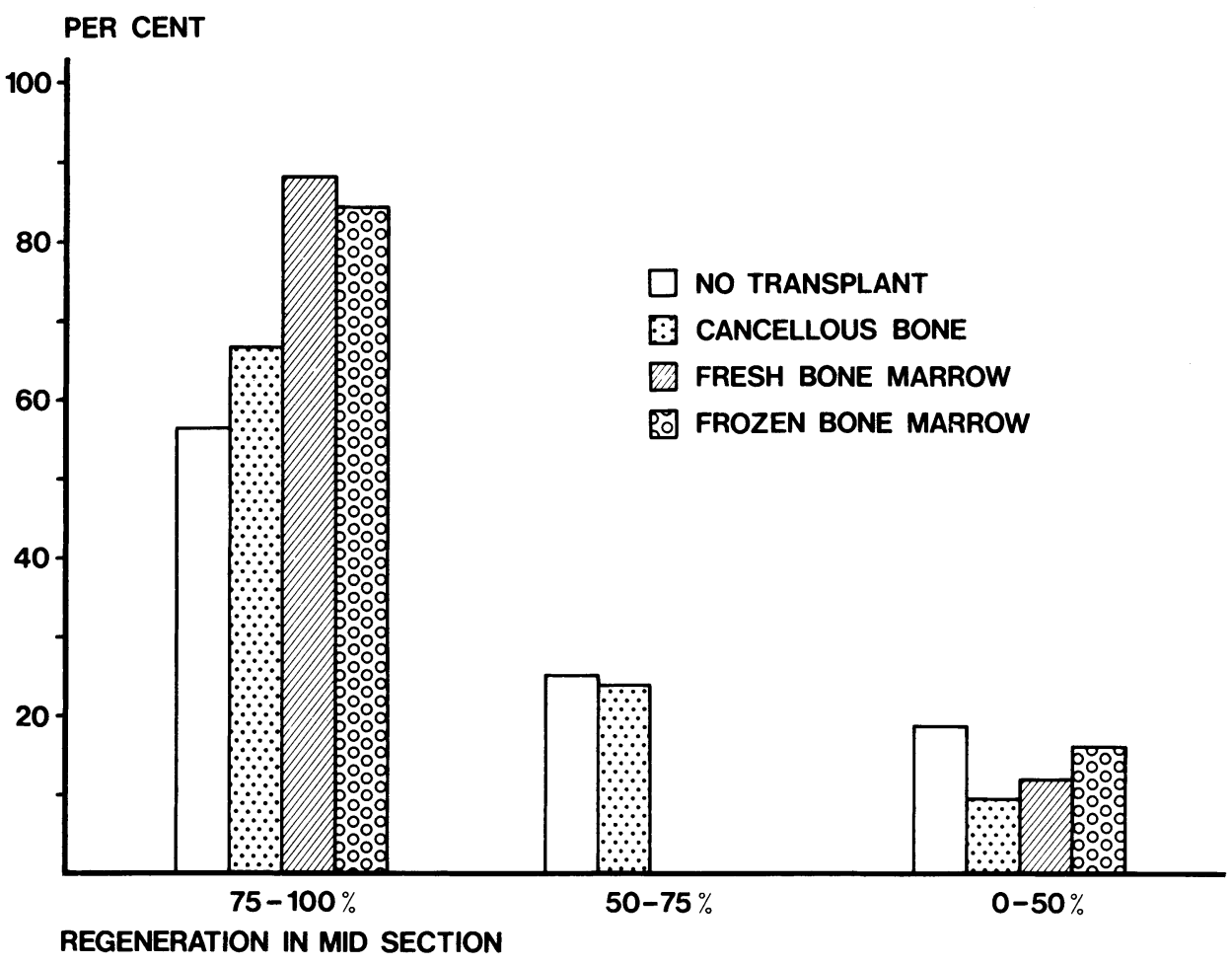

FIGURE 4. The percentage of teeth showing various degrees of regeneration in the midsection of the specimens. 


\section{PER CENT}
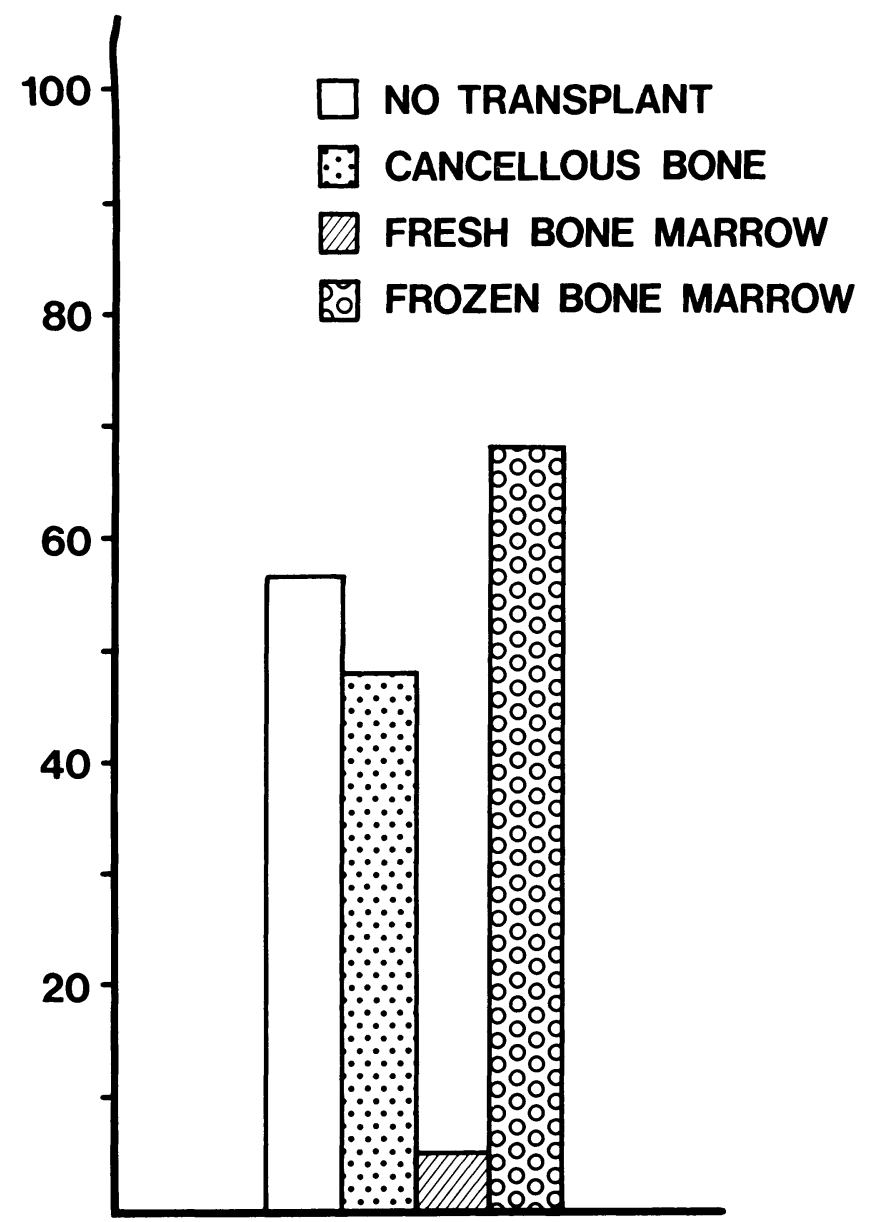

NEW ATTACHMENT

FIGURE 5. The percentage of teeth showing new attachment as defined by the formation of new cementum and periodontal ligament. the alveolar crest (Figure 7A). In two one-week specimens without graft material, the epithelium had grown $2 \mathrm{~mm}$. apical to the notch. I. In all specimens treated with grafts, the epithelial cells surrounded the marginal parts of the bone transplants (Figures 7A, 7B).

In 2 and 3 week specimens a pronounced osteogenic activity was observed. Apparently most of the osteocytes had survived transplantation of the fresh marrow transplants, while in the cancellous bone and the frozen hip bone marrow most cells appeared non-viable. Osteoblasts were present at the periphery of some grafts and new bone formation could be seen extending from the host tissue. Inflammatory cells were evident in the connective tissue at the gingival margin. Epithelial cells had proliferated along the root surface and often surrounded some of the graft particles. Total exfoliation of the graft material was seen in only one case. In most instances, new cementum formation was not apparent until the third week. The new cementum covered planed dentin as well as old cementum.

From 6 to 24 weeks the newly formed cementum increased in thickness, especially in the notch at the bottom of the defects (Figures 7B, 7C). After 24 weeks only a few areas showed well defined fiber bundles attached to the new cementum. The fibers were generally oriented parallel to the root surface, but this arrangement was also observed farther down the root where no surgery had been performed. In some defects treated with fresh bone marrow, new cementum formation was limited to the notch area. Between the epithelium and the notch area in the bottom of these defects, connective tissue was in contact with the root surface apparently without fiber attachment (Figure 8B).

Healing by ankylosis was regularly seen in intrabony defects treated with fresh hip bone marrow and was always accompanied by resorption (Figure 9). Evidence

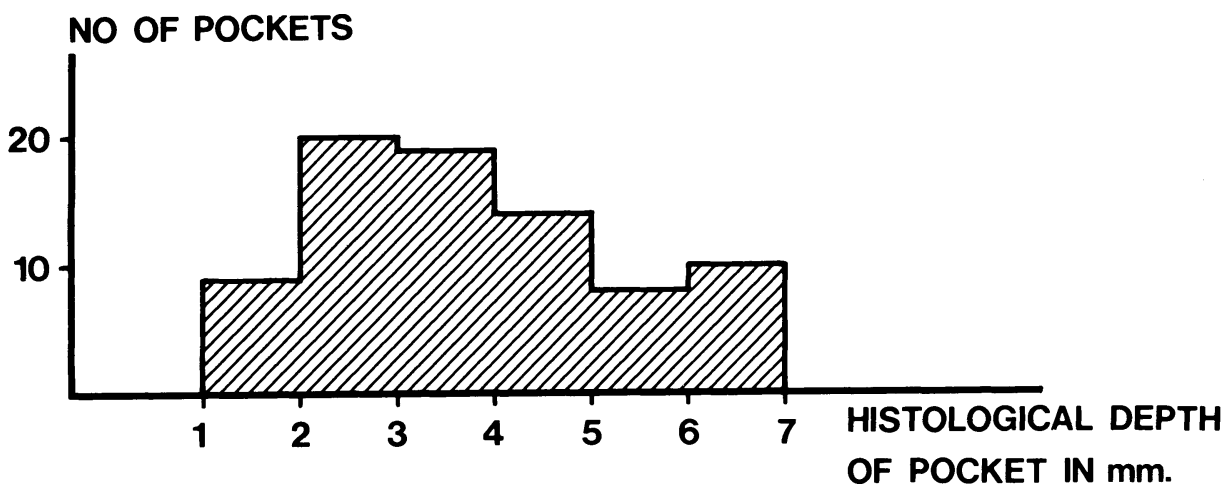

FiguRE 6. Diagram showing the variation in histological depth of the pockets following new attachment attempts. 

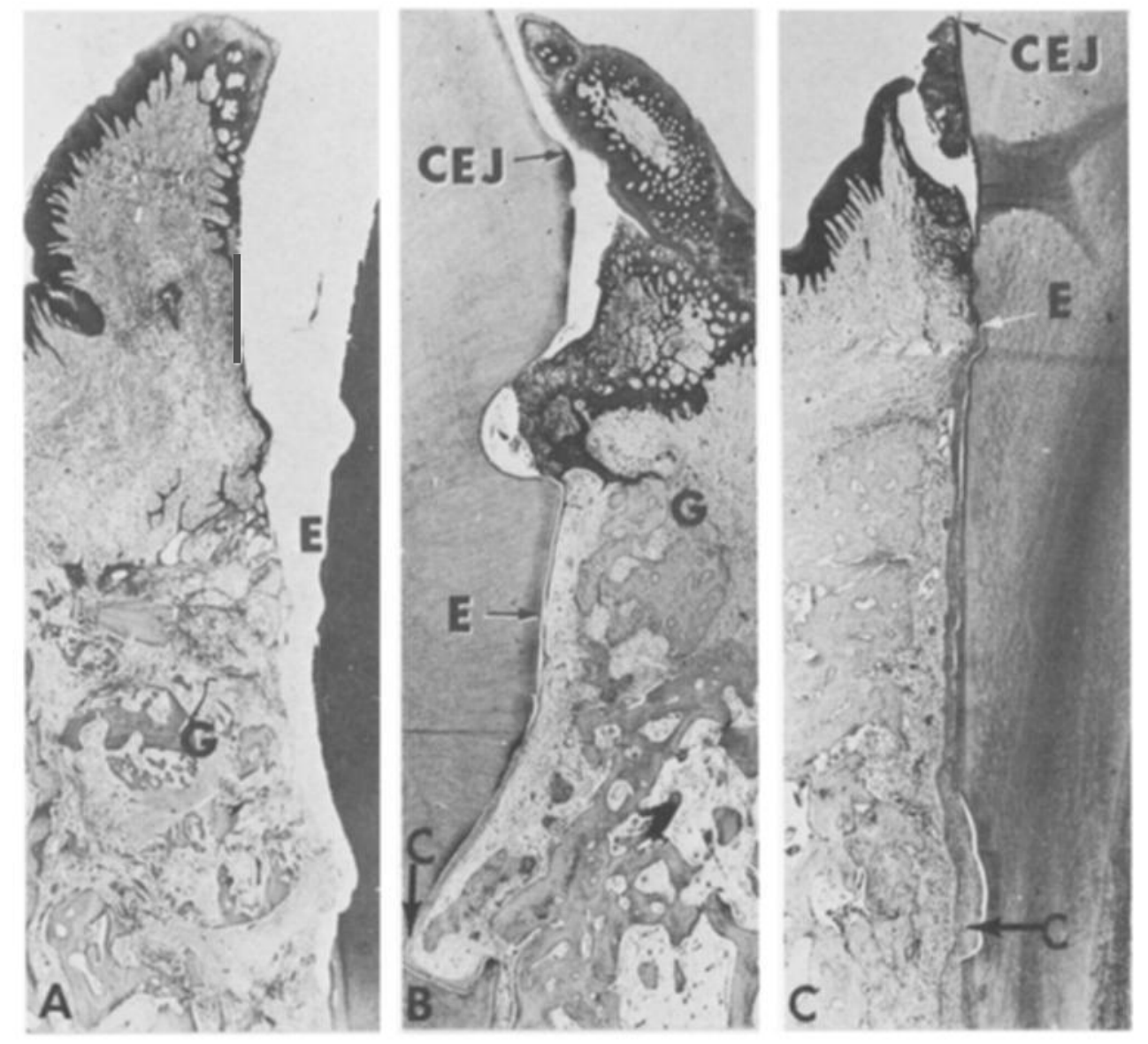

FIGURE 7. Photomicrographs demonstrating new attachment after grafting with cancellous bone $(G)$. A: One week. B: Six weeks. C: Twenty-four weeks. The epithelium (E) extends to the notch which designated the level of the alveolar crest at the time of surgery in $A$ and $C$; in $B$ the epithelium has migrated apically (arrow). C: New cementum covering planed dentin as well as old cementum in $B$ and $C$.

of resorption and subsequent healing was observed in a few specimens of the other groups.

In approximately 10 per cent of the 6 to 24 weeks specimens, the areas of new attachment demonstrated alternating zones of connective tissue attachment and epithelium adjacent to the root surface. In many specimens this epithelium appeared to represent extensions from the pocket epithelium. However, at the bottom of the defects epithelium seemed to derive from epithelial cells which were left behind during the surgical procedure or were proliferations of epithelial rests of Mallassez.

\section{The Model}

\section{Discussion}

This study has shown that three-wall intrabony defects of almost identical size can be produced in monkeys. In creating the defects, it is important to avoid damaging the tooth surface since this may interfere with the identification of the notches produced in the root surface for the assessment of new attachment obtained following treatment. When the bone was removed from the root with a bur or sharp chisel, extensive defects were produced in the root surface. However, following the removal of bone with a rounded chisel, the cementum surface was regularly maintained intact. To avoid horizontal bone loss, lesions should be created only where at least $5 \mathrm{~mm}$. of bone can be left adjacent to a neighboring tooth.

After 3-4 weeks the defects displayed an epithelial lining of the pocket. This epithelium persisted for the remaining 24 weeks. Spontaneous connective tissue attachment averaging $1 \mathrm{~mm}$. was occasionally seen in the bottom of the defects. This probably occurred following the displacement of the band or pack from the root surface, allowing the new connective tissue attachment to develop before the epithelium had migrated into the deeper parts of the lesion.

Steel bands ligated to the tooth proved to be the preferable method for maintaining the intrabony defects, but this method may also allow small portions of 

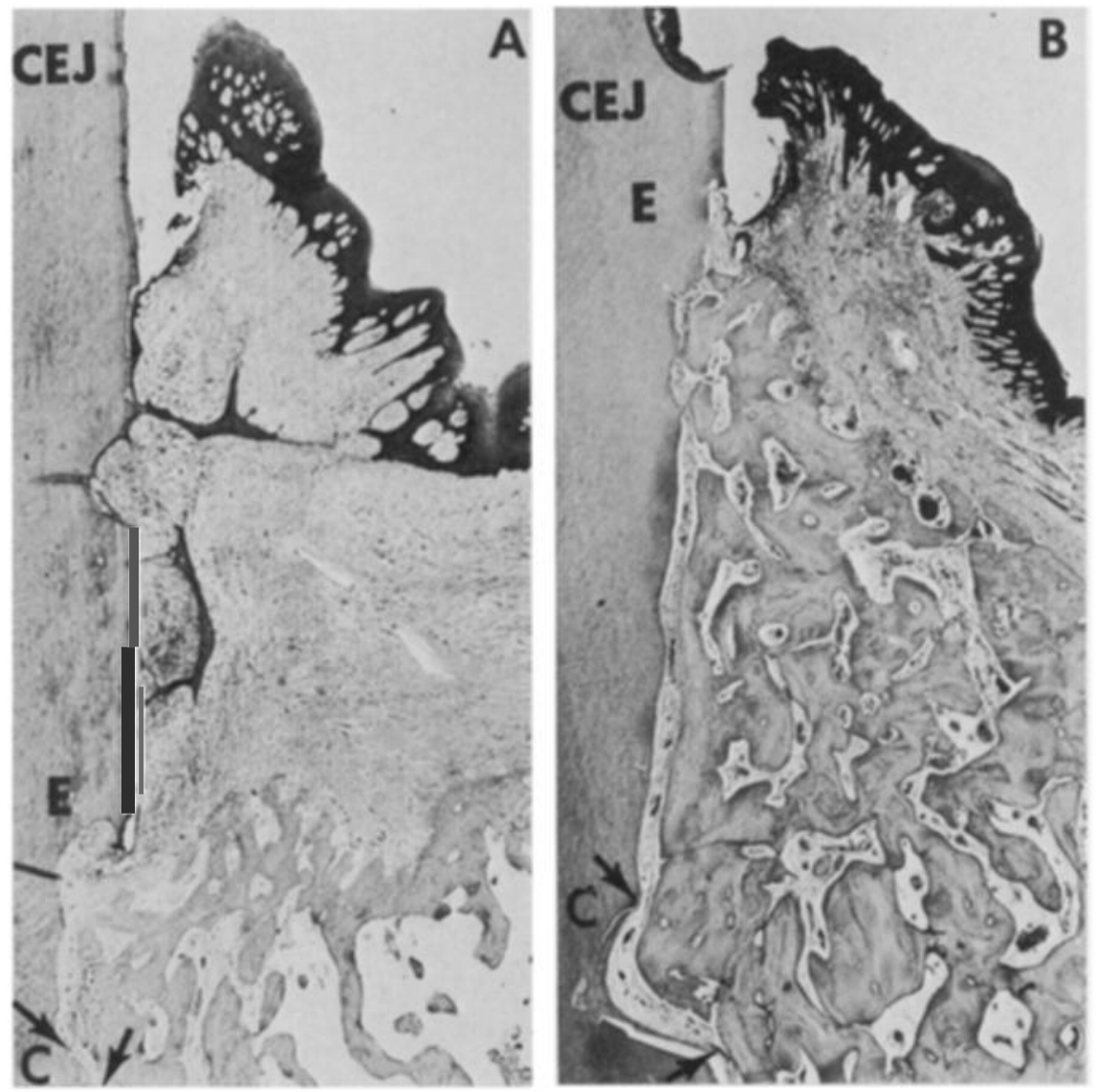

FIGURE 8. Photomicrographs showing the results of grafting with autogenous fresh bone marrow. A (six weeks): Most of the graft has exfoliated and marked horizontal bone loss has taken place. Gingival epithelium has migrated almost to the bottom of the defect $(E)$. B (24 weeks): Complete regeneration of bone. The area adjacent (CEJ) is subject to root resorption. The space between the root surface and bone is occupied by connective tissue, the fibers of which are oriented parallel to the root surface. There is no cementum formation except in the area of the notch $(C)$.

connective tissue attachment (less than $1 \mathrm{~mm}$ ) to develop in the most apical part of the lesion.

Opinions differ as to the time required to establish epithelialized periodontal pockets in animals. Krömer ${ }^{34}$ concluded from his work on dogs that artificially created two-wall intrabony pockets are completely epithelialized in 56 to 91 days following surgery. Swenson, ${ }^{35}$ who created intrabony defects in dogs with a carver and maintained them with a well-adapted band for 15 days, observed that these defects were epithelialized within 150 days. Hurt ${ }^{36}$ created two-wall defects in dogs and did not observe complete epithelialization of the lesions until the 32nd week. In the present study 4-5 mm. intrabony pockets exhibited a distinct epithelial lining after 3 to 4 weeks. The discrepancy between the results of previous studies and those of the present investigation is probably due to differences in the technique used for maintaining the defects, possible variations in the amount of inflammation, and differences in the depth of the defects.

\section{New Attachment}

The second part of the present study has shown that three-wall intrabony defects in monkeys receiving bone transplants regenerate more frequently than similar lesions without transplants. However, new attachment of periodontal tissue as characterized by the formation of a normal periodontal ligament was obtained to the same extent with and without bone grafts. This observation is in disagreement with that following treatment of bifurcation defects in monkeys, ${ }^{37}$ where new attachment was obtained more frequently using bone graft material. A possible explanation of this difference may be that three-wall intrabony defects offer better conditions for the organization of the blood clot and the subsequent healing of the wound. 

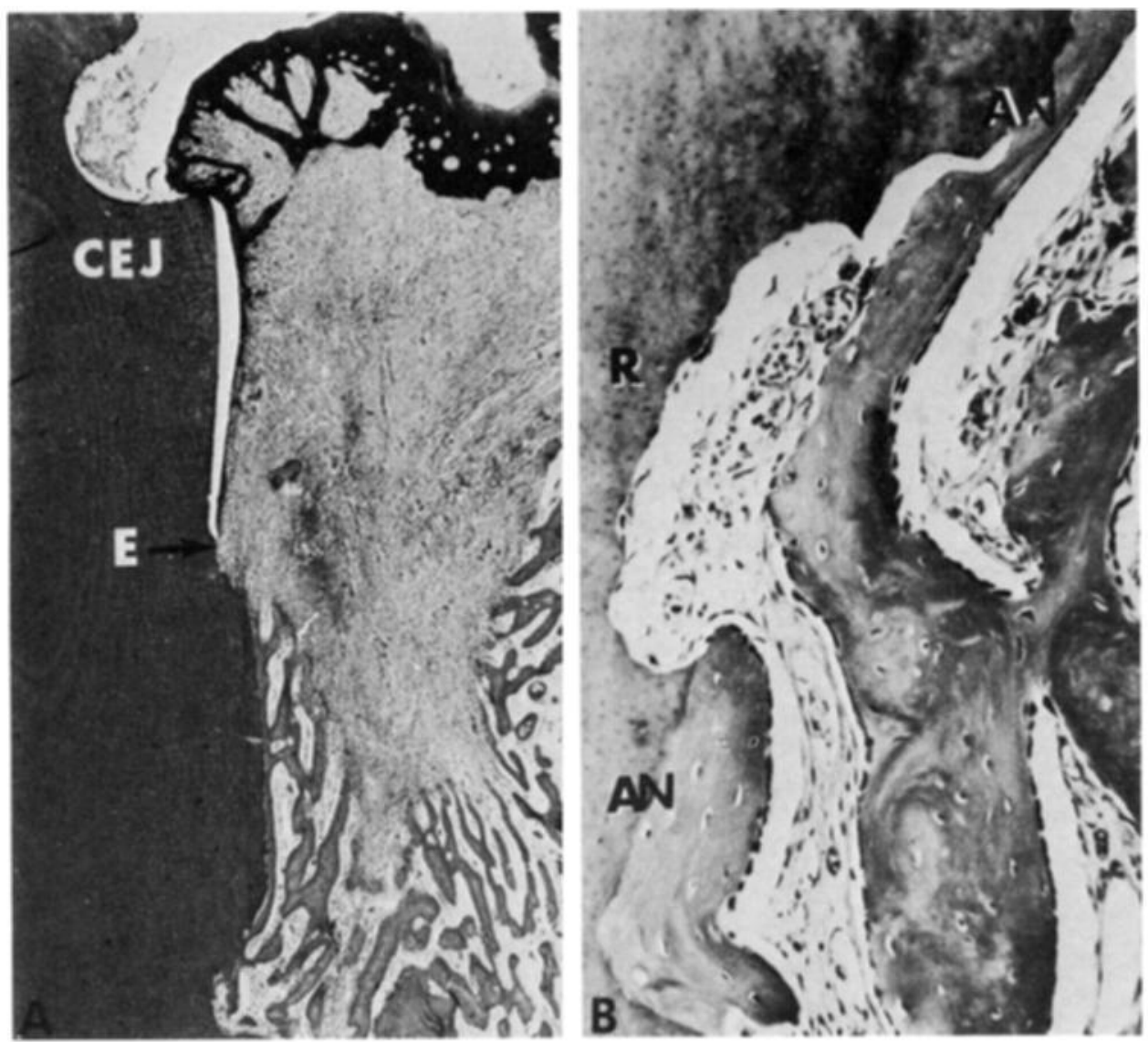

FIGURE 9. Photomicrograph of a 6-week-old specimen with fresh hip marrow showing ankylosis and root resorption $(R)$. B: Higher magnification of the ankylosed area $(A N)$, showing vital osteocytes and resorption of the root surface $(R)$.

Transplantation of autogenous fresh hip bone marrow resulted in a high degree of bone regeneration, but showed ankylosis and resorption of the root surfaces. Whether the resorption processes would have continued beyond the 24 weeks of observation cannot be determined from this series, but results from clinical cases grafted with fresh bone marrow indicate that the resorptive processes will continue. ${ }^{38,39}$

New cementum formation is a requirement for the complete reconstruction of the periodontal ligament. The hip bone marrow seemed to inhibit cells from forming cementum. This is in agreement with results obtained by Morris ${ }^{40}$ following transplantation of root dentin with bone marrow to the subcutaneous tissues in rats. He found that bone marrow produced bone that contacted the root surface by direct extension, without an intervening connective tissue space, and then resorbed and destroyed the dentin. As long as the mechanisms of inducing hard tissue resorption by hip marrow transplant are unknown, and until the effects of resorption and ankylosis on tooth function have been determined, fresh hip marrow transplants should not be used in clinical attempts to achieve new attachment.
In all specimens the gingival epithelium had migrated along the root surface. From 1 and 2 week specimens, however, it appeared that apical migration of the epithelium was arrested adjacent to areas where granulation tissue displayed a certain level of organization, or where bone grafts were in close contact with the root surface. It is noteworthy that the arrest of the migrating epithelium did not seem to require a definite fibrous attachment to the tooth.

Frequently the periodontal connective tissue displayed heavy infiltration of inflammatory cells associated with partial exfoliation of the bone grafts. Inflammation may seriously interfere with the maturation of granulation tissue and stimulate epithelial proliferation and migration into the intrabony area. This, in fact, may be a major cause of failures in new attachment attempts. Inadequate surgical procedures and infection interfering with optimal healing may thus represent important factors in preventing the development of new attachment.

The fact that new attachment in three-wall intrabony defects occurred almost as frequently when the new attachment procedures included bone grafting as when 
they did not, indicates that the induction of bone formation through the transplantation of bone particles does not play a significant role in the establishment of new attachment. The degree of infection and the rate of apical migration of the gingival epithelium seem to be essential factors in preventing the development of new connective tissue attachment. Procedures aiming at controlling these parameters have been developed and are presently being evaluated.

\section{CONCLUSIONS}

This study has shown that:

Three-wall intrabony defects showing complete epithelialization may be produced in the monkey in four weeks. This animal model may be used in evaluating various procedures for the treatment of intrabony defects.

New attachment in three-wall intrabony defects is obtained with equal success with and without autogenous bone grafts.

Intrabony lesions receiving fresh bone marrow transplants heal by ankylosis and root resorption, whereas the healing of autogenous frozen hip marrow and cancellous bone grafts is associated with new cementum formation and the establishment of a new periodontal ligament.

It is suggested that infection and epithelial downgrowth are the most important factors in preventing new attachment.

\section{REFERENCES}

1. Adams, D. F.: Transplant therapy of infrabony pockets. Periodont. Abstr. 14:63, 1966.

2. Halliday, D. G.: The grafting of newly formed autogenous bone in the treatment of osseous defects. J. Periodontol., 40:511, 1971.

3. Haggerty, P. D. and Maeda, I.: Autogenous Bone Grafts: A revolution in the treatment of vertical bone defects. J. Periodontol., 42:626, 1971.

4. Mann, W. J.: Autogenous transplant in the treatment of an intrabony pocket. Case Report. Periodontics, 2:205, 1964.

5. Nabers, C. L. and O'Leary, T. J.: Autogenous bone transplants in the treatment of osseous defects. J. Periodontol., 36:5, 1965.

6. Robinson, R. E.: Osseous coagulum for bone induction. J. Periodontol., 40:503, 1969.

7. Rosenberg, M. M.: Re-entry of an osseous defect treated by a bone implant after a long duration. J. Periodontol., 42:360, 1971.

8. Rosenberg, M. M.: Osseous regeneration of alveolar defects in periodontal disease utilizing free osseous tissue autografts. J. Periodontol., 43:47 (Abstr.), 1972.

9. Ross, S. and Cohen, D. W.: The fate of a free osseous tissue autograft. A clinical and histologic case report. Periodontics. 6:145, 1968.

10. Ewen, S. J.: Bone swaging. J. Periodontol., 36:57, 1965.

11. Ewen, S. J.: Bone swaging of interproximal craters. Bulletin of the 11th District Dental Society, 1966.

12. Ross, S., Malamed E., and Amsterdam, M.: The contiguous autogenous transplant-its rationale, indications and technique. Periodontics. 4:246, 1966.

13. Schaffer, E. M.: Cementum and dentin implants in a dog and a Rhesus Monkey. J. Periodontol., 28:125, 1957.

14. Packer, N. W., and Schaffer, E. M.: CementumDentin and Gelfoam implants in surgical periodontal pockets in dogs. Oral Surg., 18:722, 1964.

15. DeMarco, T. J., and Scalette, L. J.: The use of autogenous hip marrow in the treatment of juvenile periodontosis; a case report. J. Periodontol., 41:683, 1970.

16. Richter, H. E. Jr., Sugg, W. E. Jr., and Boyne, P. J.: Stimulation of osteogenesis in the dog mandible by autogenous bone marrow transplants. Oral Surg., 26:396, 1968.

17. Schallhorn, R. G.: The use of autogenous hip marrow biopsy implants for bony crater defects. J. Periodontol., 39:145, 1968.

18. Schallhorn, R. G., Hiatt, W. G., and Boyce, W.: Iliac transplants in periodontal therapy. J. Periodont. 41: $566,1970$.

19. Schallhorn, R. G.: Postoperative problems associated with iliac transplants. J. Periodontol., 43:3, 1972.

20. Seibert, J. S.: Reconstructive periodontal surgery. Case Report. J. Periodontol., 41:113, 1970.

21. Fried, S. L.: Bone marrow autografts and homografts into periodontal defects in dogs. J. Periodontol., 43:43 (Abstr.), 1972.

22. Bell, W. H., Hinds, E. and Arnim, S. S.: Histologic comparison of bovine and anorganic bone implants in human beings. J. Dent. Res., 37:45, 1958.

23. Bell, W. H.: Resorption characteristics of autogenous and anorganic bone implants. J. Dent. Res., 36: 698 (Abstr.), 1959.

24. Beube, F. E., and Silvers, H. F.: Influence of devitalized heterogenous bone-powder on regeneration of alveolar and maxillary bone of dogs. J. Dent. Res., 14:15, 1934.

25. Beube, F. E. and Silvers, H. F.: Further studies on bone generation with the use of boiled heterogenous bone. J. Periodontol., 7:17, 1936.

26. Cross, W. G.: Heterogenous bone graft. Dent. Pract., 5:429, 1955.

27. Forsberg, H.: Transplantation of os purum and bone chips in the surgical treatment of periodontal disease (Preliminary report). Acta Odontol. Scand., 13:235, 1956.

28. Kramer, I. R., Killey, H. C., and Wright, H. C.: The pattern of healing following implantation of heterogenous anorganic compact bone in sheep. Arch. Oral Biol., 9:671, 1964 .

29. Lyon, H., Ostrom, C. A., Losee, F. L., Hurley, L. A., and Boyne, P. J.: Host response to implants of heterogenous anorganic bone. J. Dent. Res., 38:699, 1959.

30. Melcher, A. H.: The use of heterogenous anorganic bone as an implant material in oral procedures. Oral Surg. 15:996, 1962.

31. Patur, B., and Glickman, I.: Clinical and roentgenographic evaluations of the post-treatment healing of infrabony pockets. J. Periodontol., 33:164, 1962. 
32. Older, L. B.: The use of heterogenous bovine bone implants in the treatment of periodontal pockets. J. Periodontol., 38:539, 1967.

33. Scoop, I. W., Kassouny, D. Y., Morgan, F. H.: Bovine bone (boplant). J. Periodontol., 37:400, 1966.

34. Kromer, H.: Bone homografts in the surgical treatment of cysts of the jaws and periodontal pockets. Odont. T. 68:1, D. Abs. 5:599, 1960.

35. Swenson, H. M.: Experimental periodontal pockets in dogs. J. Dent. Res. 26:273, 1947.

36. Hurt, W. C.: Epithelialization of artificially in- duced periodontal lesions in dogs. J. Periodontol., 34:120, 1963.

37. Ellegaard, B., Karring, T., Listgarten, M., and Löe, H.: New attachment after treatment of interradicular lesions. In Press, 1973.

38. Burnette, E. W.: Fate of an iliac crest graft. Case Report. J. Periodontol., 43:88, 1972.

39. Schallhorn, R. G.: Postoperative problems associated with iliac transplants. J. Periodontol., 43:3, 1972.

30. Morris, M. L.: The implantation of human dentin and cementum with autogenous red marrow into the subcutaneous tissues of the rat. J. Periodontol., 40:571, 1969.

\section{Abstracts}

\section{The Acidic Glycosaminoglycans of Gingiva of Diabetic Rats}

Kofoed, J. A. and Tocci, A. A.

J. Periodont. Res., 8:323, 1973.

The effect of insulin on both the concentration and synthesis of glycosaminoglycans (GAG) in gingiva was tested using 48 male Wistar rats and dividing them into the following 4 groups of equal size: (1) control rats, (2) pair-fed rats, (3) untreated diabetic rats, and (4) insulin treated diabetic rats. In comparison to pair-fed rats the untreated diabetic rats' total GAG concentration was reduced $35.9 \%$, the concentration of chondroitin-4-sulfate was decreased $45.2 \%$, and the concentration of hyaluronic acid was decreased $48.4 \%$, while heparin concentration was $23.8 \%$ increased. No effect was found on the other sulfate fractions. The level of the affected GAG was almost entirely restored to normal after insulin administration, with only the heparin values remaining high. Catedra De Fisiologia, Facultad De Odontologia, Universidad De Buenos Aires, Marcelo T. DeAlvar 2142, Buenos Aires, Argentina.

\section{The Nature of the Granules Within Sulcular Epithelial Cells}

Innes, P. B.

J. Periodont. Res., 8:252, 1973.

Gingivectomy specimens from clinically normal tissue associated with observable plaque-free tooth surfaces of the canine teeth of ten male adult cats were divided so that one group of tissues was stained for acid phosphatase while another was stained by the periodic acid silver methenamine technique. Autoradiography and liquid scintillation by means of radioisotopes were also used. Electron microscopic examination revealed a positive result for granules stained with the periodic acid methenamine technique which suggested a glycoprotein content. Some of the granules were shown to react positively for acid phosphatase which means that they are lysosomal in nature. The autoradiographic studies suggested that the granules are related to the production of materials which become incorporated into the extraneous cell surface coat of the sulcular epithelial cells. The liquid scintillation studies showed that the rate of synthesis of cell coat material was higher in the sulcular epithelium than in oral epithelium, which could be related to the fact that sulcular epithelium has a relatively high turnover rate and thus the cells' synthetic apparatus may have to be very active in an effort to produce an adequate cell coat. The relationship to the content of gingival sulcus fluid was discussed. Department of Anatomy, College of Medicine, University of Saskatchewan, Saskatoon, Canada, S7N oWO.

\section{Necrotizing Ulcerative Gingivitis In Mongolom and NON-MONGOLOID RETARDED INDIVIDUALS}

Brown, R. H.

J. Periodont. Res., 8:290, 1973.

To compare the prevalence of necrotizing ulcerative gingivitis in 806 mongoloid and non-mongoloid children and adults living in an institution for the mentally retarded over a period of 10 years, the records were reviewed of examinations of the gingival condition which had been made at 6- or 3-month intervals. Of the 149 mongoloid subjects, $53(35.6 \%)$ had experienced one or more episodes of necrotizing ulcerative gingivitis. Only 27 of the 657 non-mongoloid subjects $(4.1 \%)$ had been affected. Of the subjects who had experienced ulceration, $49.1 \%$ of the mongoloids and $29.6 \%$ of the non-monogoloids had recurrences. The mean ages at the time of the first recorded episode were found to be similar: that for mongoloids being 9.4 years and for non-mongoloids 9.9 years. The results showed that institutionalized mongoloid children and adults have a higher incidence of necrotizing ulcerative gingivitis as compared with institutionalized non-mongoloid adults and children, and that episodes of necrotizing ulcerative gingivitis in mongoloids resulted in severe periodontal destruction whereas in non-mongoloids destruction was less severe. University of Otago Dental School, P.O. Box 647, Dunedin, New Zealand.

\section{Quantitation of Human Dental Plaque By Turbimimetry}

Gawronski, T. H., Staat, R. H., and Folke, L. E. A. J. Dent. Res., 52:633, 1973.

Male freshman dental students that were given a prophylaxis and did not perform any oral hygiene procedures for four days were used to test a precise turbidimetric method for quantitation of noncalcified dental plaque. Results indicated that turbidimetric measurement is an accurate method for estimation of plaque quantity. Division of Periodontology, School of Dentistry, University of Minnesota, Minneapolis, Minnesota 55455. 